\title{
RESEARCH
}

Open Access

\section{Scavengers of hemoproteins as potential biomarkers for severe sepsis and septic shock}

\author{
Myrddin W. Verheij ${ }^{1}$, Ingrid Bulder ${ }^{2}$, Walter A. Wuillemin ${ }^{3}$, Carlijn Voermans ${ }^{1}$ and Sacha S. Zeerleder ${ }^{2,4,5^{*}}$
}

\begin{abstract}
Background: Despite improvements in diagnosis, interventions and supportive care, mortality among sepsis patients is still high. Research of the past decade has attempted to identify biomarkers that can accurately discriminate sepsis from other diseases with comparable symptoms to improve diagnosis, but results have been lackluster. Recent studies have shown that hemoproteins and damage-associated molecular patterns (DAMPs) such as mitochondrial DNA (mtDNA) released as the result of hemolysis play an important role in the pathogenesis of sepsis. The aim of this study was to measure plasma levels of the indirect markers for hemoproteins hemopexin, haptoglobin and heme oxygenase-1 ( $\mathrm{HO}-1)$ as well as the mitochondrial damage marker mtDNA in the plasma of a cohort of sepsis patients to determine the feasibility of their use as biomarkers in the diagnosis of sepsis.

Methods: Hemopexin, haptoglobin and HO-1 were measured in plasma by ELISA and mtDNA was measured by digital droplet PCR. Plasma levels of hemopexin, haptoglobin, HO-1 and mtDNA were measured in 32 patients with severe sepsis and 8 patients with septic shock at baseline and 4 days after admission to the ICU and in 20 healthy donors.
\end{abstract}

Results: Plasma levels of hemopexin were significantly lower and plasma levels of HO-1, haptoglobin and mtDNA were significantly higher in patients with severe sepsis and septic shock at baseline compared to healthy controls. Additionally, HO-1 levels were significantly higher in patients with septic shock compared to patients with severe sepsis. Finally, levels of HO-1 and mtDNA, but not of hemopexin, seemed to slowly revert back towards levels measured in healthy donors within 5 days after admission.

Conclusions: Our results indicate that plasma levels of the hemoprotein scavengers hemopexin, haptoglobin and HO-1 and the mitochondrial damage marker mtDNA might be useful as additional biomarkers for the early diagnosis of sepsis and disease severity.

Keywords: Sepsis, Biomarkers, Hemoproteins, Scavengers, Hemopexin, Haptoglobin, Heme oxygenase-1, Mitochondrial DNA

\footnotetext{
* Correspondence: sacha.zeerleder@insel.ch

${ }^{2}$ Department of Immunopathology, Sanquin Research and Landsteiner

Laboratory, Amsterdam, The Netherlands

${ }^{4}$ Department of Hematology and Central Hematology Laboratory, Inselspital,

Bern and Bern University Hospital, University of Bern, Bern, Switzerland

Full list of author information is available at the end of the article
}

(c) The Author(s). 2021 Open Access This article is licensed under a Creative Commons Attribution 4.0 International License, which permits use, sharing, adaptation, distribution and reproduction in any medium or format, as long as you give appropriate credit to the original author(s) and the source, provide a link to the Creative Commons licence, and indicate if changes were made. The images or other third party material in this article are included in the article's Creative Commons licence, unless indicated otherwise in a credit line to the material. If material is not included in the article's Creative Commons licence and your intended use is not permitted by statutory regulation or exceeds the permitted use, you will need to obtain permission directly from the copyright holder. To view a copy of this licence, visit http://creativecommons.org/licenses/by/4.0/. 


\section{Background}

Severe sepsis is a result of an uncontrolled immune response of the host to infection. In the area of timely diagnosis, rapid interventions and intensive supportive care, mortality rates for severe sepsis still reach $20 \%$.[13] Even in the first year after hospital discharge, mortality among sepsis survivors is high and the long-term quality of life of these patients is impaired.[4] Studies have shown that an early diagnosis and intervention in patients with severe sepsis increases survival rates.[5, 6] However, symptoms are often variable and non-specific, making early diagnosis of sepsis a major challenge.[7] Therefore, there is an absolute need to identify biomarkers that can discriminate the presence of sepsis from other diseases and predict severity at early stages of this process.[7].

Sepsis is characterized by extensive cell death of hematopoietic as well as parenchymal cells, as evidenced by the systemic release of damage-associated molecular patterns (DAMPs) such as cell-free DNA.[8-10] Cell death is accompanied by disintegration of mitochondrial membranes with subsequent release of DAMPs in the form of hemoproteins containing heme and iron from the respiratory chain.[11] Changes in red blood cell (RBC) energy metabolism to maintain redox balance, alteration of RBC membrane properties, complement activation, pathogens invading RBCs and endothelial cell activation with subsequent microvascular RBC destruction result in hemolysis and subsequent systemic release of cell-free hemoglobin, cell-free heme and iron during sepsis. Finally, death of skeletal muscle cells accompanying sepsis results in the systemic release of myoglobin containing heme and iron.[11, 12] Endogenous plasmaand cellular systems protect the organism from the negative effects of hemoproteins and iron.[11] Cell-free hemoglobin and cell-free heme are scavenged by the plasma proteins haptoglobin and hemopexin, respectively. Heme oxygenase-1 (HO-1), an enzyme that is inducible by free heme and iron, catalyzes the degradation of heme into iron, biliverdin and CO intracellularly.[11] Subsequently, iron is neutralized by ferritin, the upregulation of which is coupled to the induction of HO-1. Previous studies have highlighted the important role of free heme in the pathogenesis of sepsis[2], and have linked plasma levels of haptoglobin and hemopexin to severity and outcome of disease.[13, 14] Moreover, increased HO-1 mRNA expression and protein levels have been shown to exert protection in experimental animal models for sepsis. [15, 16] Finally, mitochondrial DNA (mtDNA) released from mitochondria upon cell death has been shown to elicit immune responses through activation of TLR9 and the NLRP3 inflammasome.[17] In line with this, several studies and clinical trials (reviewed in Harrington et al., (2017)) have found mtDNA levels to be elevated in patients with sepsis, pointing to a probably role of mtDNA in sepsis pathogenesis.[18] As such, we questioned whether indirect markers for hemoproteins such as their respective scavengers and mitochondrial damage markers such as mtDNA might be useful as biomarkers for the diagnosis of severe sepsis in clinical practice.

In this study, we measured plasma levels of haptoglobin, hemopexin, HO-1 and mtDNA in patients with severe sepsis and septic shock and healthy donors to identify potentially novel biomarkers for severe sepsis and septic shock.

\section{Materials and methods \\ Patients}

This study was approved by the medical ethical committees of the involved institutions, and all patients and healthy volunteers or their legal representatives gave written informed consent before inclusion. Sepsis patients were initially recruited as part of a randomized, double-blind placebo controlled trial aiming to investigate the efficacy and safety of C1-Inhibitor administration for the treatment of severe sepsis and septic shock.[19] Whole blood and plasma samples were taken from these patients at admission $(t=0)$, and daily thereafter for 4 consecutive days (5 time-points in total).[19] Plasma samples from 20 healthy Dutch volunteers were also obtained. Plasma samples were stored at $-80^{\circ} \mathrm{C}$ until further analysis. For analyses of baseline $(t=0)$ measurements, all patient samples were included. For the measurements over time, only samples of patients treated with placebo and not $\mathrm{C} 1$-inhibitor were included in the analysis.

\section{Laboratory analyses \\ Digital droplet $P C R$}

DNA was isolated from plasma using the QIAamp DSP virus kit (Qiagen), following the protocol included in the kit. For vacuum steps, instead of using vacuum technology, an Eppendorf centrifuge was used to spin down samples. $200 \mu \mathrm{l}$ plasma was used for isolation, and reagent volumes for isolation were adjusted accordingly. DNA samples were thawed and diluted 1 in 5 in DNasefree water. A ddPCR reaction mixture for the appropriate number of samples, a control DNA sample with known quantity (isolated from MNCs and diluted 1 in 10 in DNase-free water) and a no-template control (NTC) was prepared with $11 \mu \mathrm{l} 2 \mathrm{x}$ ddPCR Mastermix (no dUTP) (Biorad), $1 \mu \mathrm{l} 20 \mathrm{x} \mathrm{ddPCR}^{\mathrm{ma}}$ Copy Number Assay: ND1, Human (FAM) (Biorad, unique assay ID

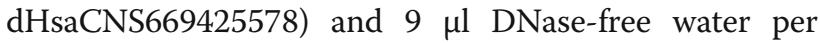
sample. For each DNA sample, $2 \mu \mathrm{l}$ of pre-diluted DNA was added to $42 \mu \mathrm{l}$ of ddPCR reaction mix. Droplets were generated with a QX200 droplet generator 
(Biorad), following the accessory instruction manual. $40 \mu \mathrm{l}$ of droplets from the top wells of the cartridge were transferred to a 96-well TwinTec PCR plate (semiskirted, green, Eppendorf). After sealing the plate, the PCR was carried out in a T100 thermal cycler (Biorad), with the heated lid set to $105{ }^{\circ} \mathrm{C}$ and a sample volume of $40 \mu$ l. One cycle of enzyme activation was performed ( 95 ${ }^{\circ} \mathrm{C}$ for $10 \mathrm{~min}$ ), followed by 40 cycles of amplification $\left(95^{\circ} \mathrm{C}\right.$ for $30 \mathrm{~s}, 60^{\circ} \mathrm{C}$ for $1 \mathrm{~min}$ ) and finally one cycle of enzyme deactivation $\left(98^{\circ} \mathrm{C}\right.$ for $\left.10 \mathrm{~min}\right)$. A ramp rate of $2{ }^{\circ} \mathrm{C} /$ second was maintained for all steps. After PCR was complete, the PCR plate was placed in a QX200 droplet reader (Biorad) for counting of the droplets. Results were analyzed using Quantasoft software (Biorad), and absolute values of mtDNA (ND1) (copies/ $\mu \mathrm{l})$ were calculated for each DNA sample by correcting for the corresponding dilution values.

\section{ELISA}

Heme oxygenase-1, haptoglobin and hemopexin were measured in plasma by ELISA. HO-1 was measured using a commercially available human heme oxygenase1 matched antibody pair kit (Abcam, ab215401). Haptoglobin was measured using a commercially available human haptoglobin DuoSet ELISA (R\&D Systems, DY8465-05). Hemopexin was measured using in-house capture and (biotinylated) detection antibodies. All coating steps were performed in PBS, samples and standard curves were measured diluted in high performance ELISA-buffer (HPE) and biotinylated detection antibodies were diluted in HPE. Poly-HRP diluted 1:10.000 was used for detection.

\section{Statistical analyses}

Results are expressed as mean \pm SD or median with interquartile range. Statistical analyses were carried out using Graphpad Prism 8 software. Differences between groups were analyzed using the nonparametric, twotailed Mann-Whitney U test for unpaired samples and the nonparametric Wilcoxon matched-pairs signed rank test was used for paired samples. A p-value at or below 0.05 was considered statistically significant.

\section{Results}

Measurement of plasma levels of hemoprotein scavengers and mitochondrial damage markers

We measured levels of indirect markers for hemoproteins such as hemopexin, haptoglobin and HO-1 and mtDNA in the plasma of 40 patients with a median age of 64 yrs (range 28-75 yrs) with sepsis (32 severe sepsis and 8 septic shock patients) and in the plasma of 20 healthy controls. Plasma levels of hemopexin were significantly lower in the patients with severe sepsis and septic shock at $\mathrm{t}=0$ compared to the healthy controls $(P<0.0001)$. This indicates that hemopexin is consumed upon complexation with cell-free heme, which is released from hemoproteins into the plasma in patients suffering from sepsis (Fig. 1 a). In contrast, plasma levels of HO-1, haptoglobin and mtDNA were significantly higher in the patients with severe sepsis and septic shock at $\mathrm{t}=0$ compared to the healthy controls $(P<0.0001$ and $P=0.0025$, respectively) (Fig. $1 \mathrm{a}$ ). $\mathrm{HO}-1$ is an intracellular enzyme that is upregulated upon stress, and is normally not secreted. Mitochondrial DNA can be released
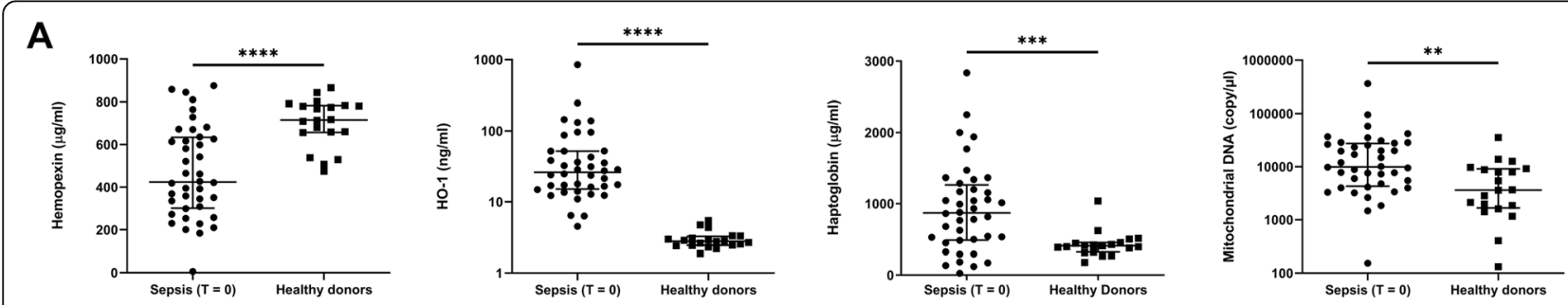

B
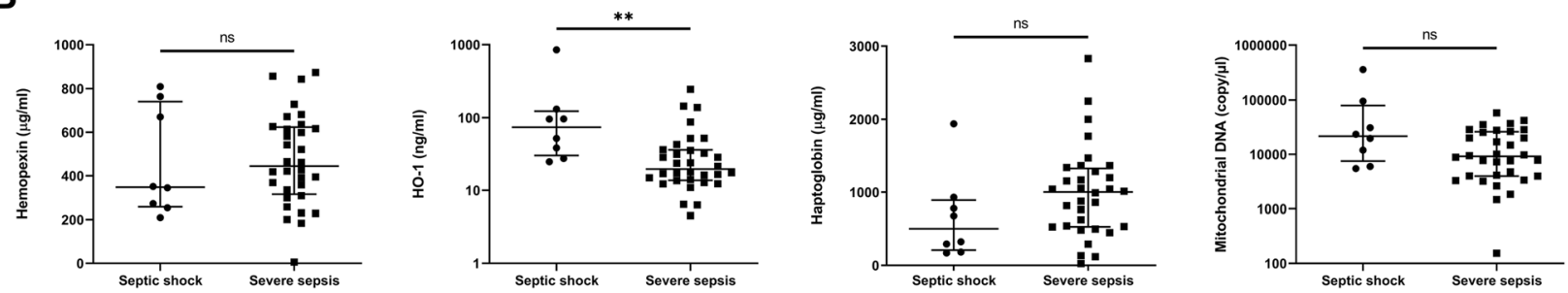

Fig. 1 Hemoprotein scavengers and mitochondrial damage markers in sepsis patients at baseline and healthy donors. a Plasma levels of hemopexin, HO-1, haptoglobin and mitochondrial DNA are shown in healthy donors $(n=20)$ and in sepsis patients at baseline $(n=40)$. $\mathbf{b}$ Baseline $(\mathrm{t}=0)$ plasma levels of hemopexin, $\mathrm{HO}-1$, haptoglobin and mitochondrial DNA are shown in patients with severe sepsis $(n=32)$ and patients with septic shock $(n=8)$. Data are presented as median \pm interquartile range. Groups have been compared using Mann-Whitney Rank Sum Test; $P<$ 0.05 was considered significant. ${ }^{* *} P<0.01,{ }^{* * * *} P<0.0001$ 
from mitochondria and cells in case of cellular stress and from cells undergoing apoptosis or necrosis.[20].

Plasma levels of HO-1 were significantly higher in patients with septic shock $(n=8)$ compared to patients with severe sepsis $(n=32)$ at $\mathrm{t}=0(P=0.0054)$. No difference in plasma levels of hemopexin, haptoglobin and mtDNA was observed when comparing patients with severe sepsis and septic shock (Fig. 1b). Overall, our data suggest that plasma levels of hemopexin, HO-1, haptoglobin and mtDNA are altered in sepsis, and as such might be useful as biomarkers for the diagnosis of the disease.

Of the 40 patients included in our study, 20 patients were not subjected to an intervention treatment in the context of the study and only received conventional standard supportive care for sepsis (which consisted of antibiotics, intravenous fluid substitutions and vasopressor therapy).[19] To determine whether plasma levels of hemopexin, HO-1, haptoglobin and mtDNA changed over time with standard care, we also measured these plasma levels in patients at day 4 after diagnosis. Both HO-1 and mtDNA were significantly lower at day 4 compared to baseline $(P=0.0071$ and $P=0.0016$, respectively), whereas hemopexin and haptoglobin levels did not change significantly in the first 4 days after diagnosis (Fig. 2). Only a small number of septic shock patients could be included in this analysis, and no clear differences were seen when comparing patients with severe sepsis and with septic shock.

\section{Discussion}

In this study, we assessed the applicability of the scavengers of hemoproteins hemopexin, haptoglobin and HO-1 and the mitochondrial damage marker mtDNA as biomarkers for the diagnosis of sepsis.

In a cohort of 40 patients suffering from severe sepsis or septic shock, we found plasma levels of hemopexin to be significantly decreased while plasma levels of HO-1, haptoglobin and mtDNA were significantly increased. The decreased levels of hemopexin are in line with research from other groups, which showed that low concentrations of hemopexin in serum are associated with a worse outcome in patients with septic shock[2] and which found plasma levels of hemopexin to be significantly higher in survivors of sepsis compared to nonsurvivors.[13] Upon complexation with heme, hemopexinheme complexes are endocytosed by macrophages and hepatocytes after binding to CD91, the primary receptor for hemopexin-heme complexes.[21] This mechanism is likely causing the decrease of hemopexin seen in our patient samples. Interestingly, we found haptoglobin levels to be significantly higher in sepsis patients compared to healthy donors, in stark contrast with hemopexin. This may be due to a difference in dynamics of the two proteins, with the early induction of haptoglobin possibly being much faster and stronger than the induction of hemopexin. These data suggest that hemopexin, HO-1, haptoglobin and mtDNA could be potential biomarkers to be used in the diagnosis of sepsis. To further determine whether these markers can distinguish sepsis from other diseases, plasma levels of these markers should be compared with other conditions that fit the criteria used to diagnose sepsis, such as acute pancreatitis or trauma.[22].

We further show that, although our sample sizes are limited, patients with septic shock seem to have higher plasma levels of HO-1 and mtDNA, and lower levels of hemopexin compared to patients with severe sepsis. Finally, we found that plasma levels of HO-1 and mtDNA, on average, decrease again after several days of standard care treatment. Our data suggest that treatment may influence these markers and indicate that these markers may also provide extra information on the severity of the disease.

\section{Conclusions}

In conclusion, we have shown that plasma levels of hemopexin, HO-1, haptoglobin and mtDNA are altered in patients with severe sepsis and septic shock and that they could potentially be valuable biomarkers to be used in the diagnosis of sepsis. However, further research using larger sample groups allowing for the determination of both sensitivity and specificity of these markers is needed to confirm this.
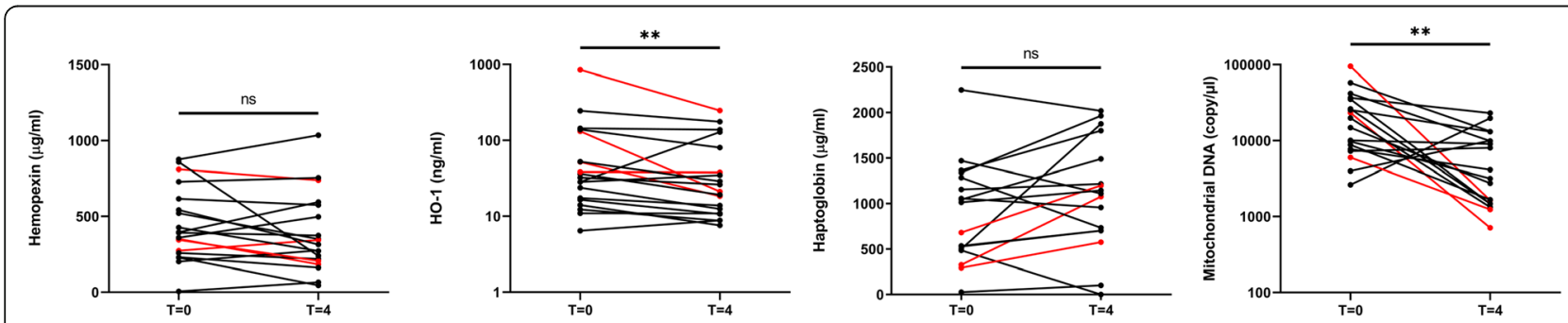

Fig. 2 Hemoprotein scavengers and mitochondrial damage markers in sepsis patients over time. Plasma levels of hemopexin, HO-1, haptoglobin and mitochondrial DNA are shown in severe sepsis patients (black) and septic shock patients (red) at baseline $(\mathrm{t}=0)(n=19, n=18$ for haptoglobin and $\mathrm{mtDNA}$ ) and at day 4 after admission $(\mathrm{t}=4)(n=19, \mathrm{n}=18$ for haptoglobin and $\mathrm{mtDNA})$. Groups have been compared using Wilcoxon Rank Sum test. $P<0.05$ was considered significant. ${ }^{* *} P<0.01$ 


\section{Abbreviations}

DAMP: Damage-associated molecular pattern; mtDNA: mitochondrial DNA; HO-1: heme oxygenase-1

\section{Acknowledgements}

Not applicable.

\section{Authors' contributions}

All authors contributed to study conception and design. MWV and IB collected the data and performed the experiments. MWV performed data analysis and statistics. MWW wrote the first draft of the manuscript. The manuscript was critically reviewed and edited by SSZ and CV and all authors read and approved the final version.

\section{Funding}

This work was financially supported by the Landsteiner Foundation for Blood Transfusion Research, grant F1719 (M.V., I.B., C.V. and S.Z.).

\section{Availability of data and materials}

Data in the current study is available from the corresponding author upon reasonable request.

\section{Declarations}

Ethics approval and consent to participate

This study was approved by the medical ethical committees of the involved institutions, and all patients and healthy volunteers or their legal representatives gave written informed consent before inclusion.

\section{Consent for publication}

Not applicable.

\section{Competing interests}

The authors declare that they have no competing interests.

\section{Author details}

${ }^{1}$ Department of Hematopoiesis, Sanquin Research and Landsteiner Laboratory, Amsterdam, The Netherlands. 'Department of Immunopathology, Sanquin Research and Landsteiner Laboratory, Amsterdam, The Netherlands. ${ }^{3}$ Department of Hematology and Central Hematology, Department of Internal Medicine, Kantonsspital Lucerne, Lucerne and University of Bern, Bern, Switzerland. ${ }^{4}$ Department of Hematology and Central Hematology Laboratory, Inselspital, Bern and Bern University Hospital, University of Bern, Bern, Switzerland. ${ }^{5}$ Department of Biomedical Research, University of Bern, Bern, Switzerland.

Received: 12 January 2021 Accepted: 3 March 2021

Published online: 09 March 2021

References

1. Annane D, Bellissant E, Bollaert P-E, Briegel J, Confalonieri M, De Gaudio R, et al. Corticosteroids in the treatment of severe sepsis and septic shock in adults: a systematic review. Jama. 2009;301(22):2362-75.

2. Larsen R, Gozzelino R, Jeney V, Tokaji L, Bozza FA, Japiassú AM, et al. A central role for free heme in the pathogenesis of severe sepsis. Science translational medicine. 2010;2(51):51ra71-1.

3. van der Poll T, van de Veerdonk FL, Scicluna BP, Netea MG. The immunopathology of sepsis and potential therapeutic targets. Nat Rev Immunol. 2017:17(7):407.

4. Winters BD, Eberlein M, Leung J, Needham DM, Pronovost PJ, Sevransky JE. Long-term mortality and quality of life in sepsis: a systematic review. Critical care medicine. 2010;38(5):1276-83.

5. Kumar A, Roberts D, Wood KE, Light B, Parrillo JE, Sharma S, et al. Duration of hypotension before initiation of effective antimicrobial therapy is the critical determinant of survival in human septic shock. Critical care medicine. 2006:34(6):1589-96.

6. Zambon M, Ceola M, Almeida-de-Castro R, Gullo A, Vincent J-L. Implementation of the Surviving Sepsis Campaign guidelines for severe sepsis and septic shock: we could go faster. J Crit Care. 2008;23(4):455-60.

7. Pierrakos C, Vincent J-L. Sepsis biomarkers: a review. Critical care. 2010;14(1): R15.
8. Hotchkiss RS, Nicholson DW. Apoptosis and caspases regulate death and inflammation in sepsis. Nat Rev Immunol. 2006;6(11):813-22.

9. van der Meer AJ, Kroeze A, Hoogendijk AJ, Soussan AA, van der Schoot CE, Wuillemin WA, et al. Systemic inflammation induces release of cell-free DNA from hematopoietic and parenchymal cells in mice and humans. Blood advances. 2019;3(5):724

10. Zeerleder S, Zwart B, Wuillemin WA, Aarden LA, Groeneveld AJ, Caliezi C, et al. Elevated nucleosome levels in systemic inflammation and sepsis. Critical care medicine. 2003:31(7):1947-51.

11. Van Avondt K, Nur E, Zeerleder S. Mechanisms of haemolysis-induced kidney injury. Nature Reviews Nephrology. 2019:1-22.

12. Effenberger-Neidnicht $K$, Hartmann M. Mechanisms of hemolysis during sepsis. Inflammation. 2018:41(5):1569-81.

13. Janz DR, Bastarache JA, Sills G, Wickersham N, May AK, Bernard GR, et al. Association between haptoglobin, hemopexin and mortality in adults with sepsis. Critical care. 2013;17(6):R272.

14. Jung JY, Kwak YH, Kim KS, Kwon WY, Suh GJ. Change of hemopexin level is associated with the severity of sepsis in endotoxemic rat model and the outcome of septic patients. J Crit Care. 2015;30(3):525-30.

15. Chung SW, Liu X, Macias AA, Baron RM, Perrella MA. Heme oxygenase-1derived carbon monoxide enhances the host defense response to microbial sepsis in mice. J Clin Investig. 2008:118(1):239-47.

16. Fujii H, Takahashi T, Nakahira K, Uehara K, Shimizu H, Matsumi M, et al. Protective role of heme oxygenase-1 in the intestinal tissue injury in an experimental model of sepsis. Critical care medicine. 2003;31(3):893-902.

17. Nakahira K, Hisata S, Choi AM. The roles of mitochondrial damageassociated molecular patterns in diseases. Antioxid Redox Signal. 2015; 23(17):1329-50

18. Harrington J, Choi AM, Nakahira K. Mitochondrial DNA in sepsis. Curr Opin Crit Care. 2017;23(4):284

19. Caliezi C, Zeerleder S, Redondo M, Regli B, Rothen H-U, Zürcher-Zenklusen $\mathrm{R}$, et al. C1-inhibitor in patients with severe sepsis and septic shock: beneficial effect on renal dysfunction. Critical care medicine. 2002;30(8): $1722-8$

20. Miliotis S, Nicolalde B, Ortega M, Yepez J, Caicedo A. Forms of extracellular mitochondria and their impact in health. Mitochondrion. 2019:48:16-30.

21. Hvidberg V, Maniecki MB, Jacobsen C, Højrup P, Møller HJ, Moestrup SK Identification of the receptor scavenging hemopexin-heme complexes. Blood. 2005;106(7):2572-9.

22. Mayr FB, Yende S, Angus DC. Epidemiology of severe sepsis. Virulence. 2014 5(1):4-11

\section{Publisher's Note}

Springer Nature remains neutral with regard to jurisdictional claims in published maps and institutional affiliations.
Ready to submit your research? Choose BMC and benefit from:

- fast, convenient online submission

- thorough peer review by experienced researchers in your field

- rapid publication on acceptance

- support for research data, including large and complex data types

- gold Open Access which fosters wider collaboration and increased citations

- maximum visibility for your research: over $100 \mathrm{M}$ website views per year

At BMC, research is always in progress.

Learn more biomedcentral.com/submission 